\title{
The Economics of Fixed Cost Recovery by Utilities
}

Economics provides policymakers guidance when they must depart from efficient pricing (equal to societal marginal cost) to cover an electric utility profit shortfall. Options include raising volumetric retail prices, tiered pricing, fixed charges, minimum bills, and demand charges. There is no ideal policy, but balancing efficiency and equity suggests using a combination of fixed charges and increased volumetric prices. Economics does not support the use of demand charges or minimum bills.

\section{Severin Borenstein ${ }^{1}$}

Severin Borenstein is E.T. Grether Professor of Business and Public Policy at U.C. Berkeley's Haas School of Business and Faculty Researcher at the Energy Institute at Haas. He has conducted research on electricity markets for more than 20 years. He served on the Governing Board of the California Power Exchange in 1997-2003. In 201213, he served on the Emissions Market Assessment Committee, which advised the California Air Resources Board on the operation of California's cap-and-trade market for greenhouse gases. The views presented here are those of the author only and do not reflect those of any government agency or university.

This article was prepared as part of a technical report, Recovery of Utility Fixed Costs: Utility, Consumer, Environmental and Economist Perspectives, which was funded by the Energy Policy and Systems Analysis Office and the National Electricity Delivery Division of the U.S. Department of Energy's Office of Electricity Delivery and Energy Reliability under Lawrence Berkeley National Laboratory Contract No. DE-AC02$05 \mathrm{CH} 11231$.

For their valuable comments, the author expresses his gratitude to Jim Bushnell, Andrew Campbell, Lucas Davis, Jim Tracy, and participants in the $21^{\text {st }}$ annual POWER research conference at U.C. Berkeley in March 2016.

\section{Introduction}

Among the many claims about the lessons that economics teaches for fixed-cost recovery, the most common is that fixed costs should be recovered with fixed charges. Standard microeconomics, however, has very little to say directly about how utilities

\footnotetext{
${ }^{1}$ Email: severinborenstein@ berkeley.edu. Haas School of Business, University of California, Berkeley, CA, 947201900 .
} 
should recover fixed costs, and certainly nothing as simple as this claim. Rather, microeconomics offers fairly clear direction on how volumetric prices for electricity should be set to maximize efficiency, that is, to generate the greatest total value for the economy.

The simple guidance on volumetric pricing of electricity is that the retail price of a kilowatt-hour $(\mathrm{kWh})$ should reflect society's full short-run marginal cost of supplying it. To be clear, "society's" cost includes not just the marginal fuel, labor, capital, and other production costs of the utility, but also the externalities caused by generating and selling that incremental $\mathrm{kWh}$ of power. Those externalities include greenhouse gas emissions, local air pollution, and other disamenities from the presence of generating stations, as well as transmission and distribution lines. ${ }^{1}$ The focus is on short-run social marginal cost, because at any point in time price should reflect the incremental cost of producing one more unit, which will likely be higher when production capacity is strained than when there is plenty of excess capacity.

Largely because of the existence of fixed costs, however, setting the volumetric price of electricity equal to its full social marginal cost in many cases won't raise sufficient revenue to cover the utility's total costs, though the size of the shortfall will depend on many attributes of costs and demand. ${ }^{2}$ The shortfall raises the critical question of the most efficient and equitable way for the utility to raise additional revenue. In this article, I present an economist's view of a number of alternatives that have been proposed to allow a utility to recover its costs, including fixed going-forward costs that the utility incurs each period, as well as sunk costs that result from past decisions and actions.

In the next section, I briefly outline the foundational principle of economic efficiency in market transactions, which underlies all economic analyses of pricing. In the second section, I apply this principle to electricity pricing and explain why it is likely to lead to a revenue shortfall. The third section then analyzes an array of alternative proposals that allow utilities to recover additional revenue. Though the focus is primarily on economic efficiency, I also discuss equity considerations and impact on lower-income customers. My conclusion is that there is no perfect approach to increasing revenue, but some approaches make much more sense than others. Once the options are narrowed, policymakers face a fundamental tradeoff between economic efficiency and equity. 


\section{The economic efficiency of pricing}

The idea that economic efficiency is maximized when price reflects full short-run social marginal cost (SMC) is a bedrock principle of microeconomics, because it is straightforward to show that any departure from SMC is likely to reduce the economic value that the industry can create. Producing a good requires inputs — labor, fuel, machinery, land, etc. - and those inputs have alternative uses. The price of an input is generally a good indicator of its value in its next best use, so economics suggests that the inputs should only be brought together to produce this good if the value of this good to whoever consumes it exceeds the value of all the inputs necessary to make it. Setting price equal to short-run social marginal cost creates the incentive to consume an incremental unit of the good if and only if one values it more than the value that the inputs would create in their next best use. ${ }^{3}$ At the same time, customers who are considering an investment in energy efficiency receive a price signal that accurately reflects the social value of the savings such an investment would create.

To illustrate, let's say the incremental input costs of producing one additional unit of a hypothetical good add up to $\$ 7.25$, but the production process also creates a negative externality (some sort of pollution, for instance) that imposes an additional cost of $\$ 1.75$. If one sets the price for this good at $\$ 9$, then everyone who buys it values it more than $\$ 9$. As a result, there is no unit purchased that is valued less than the collection of inputs (including pollution) that went into making it and every unit purchased is valued more than the collection of inputs.

But what if the price for the good were set at $\$ 12$ ? Then anyone who valued an additional unit of the good more than $\$ 9$, but less than $\$ 12$, would not buy it. This would be value-destroying, because the value that could have been created by putting together inputs with a cost to society of $\$ 9$ in order to create a good that gives some specific buyer with a value of, say, $\$ 11$ would not be created. The failure to make that deal is a loss of $\$ 2$ of value to society. ${ }^{4}$ And there are likely to be many such losses among customers who value the good more than $\$ 9$ and less than $\$ 12$. To economists, these losses illustrated in Figure 1 by the upper (pink) triangle — are known as "deadweight loss" or, equivalently, a loss in economic efficiency. 


\section{Figure 1. Illustration of deadweight loss (DWL) from pricing above or below social marginal cost}

In practical terms, for example, if we price electricity at $\$ 0.22$ per $\mathrm{kWh}$ when its true SMC is $\$ 0.12$ (including all pollution externalities), then we might discourage someone from purchasing an electric vehicle when they would have done so had they been able to buy electricity at the true SMC.

Deadweight loss also is created if a good is priced below its SMC. If the hypothetical good illustrated in Figure 1 were priced at \$5, then anyone who valued the good above $\$ 5$ would purchase it. But if they valued it less than $\$ 9$, the value they would be getting from the good would not be great enough to justify all the inputs (including pollution) that went into making it. The deadweight loss created by such underpricing is illustrated by the lower (blue) triangle in Figure 1. For instance, if there is a buyer who values the good at $\$ 7.25$, that purchase of the good would generate $\$ 1.75$ in deadweight loss or, put differently, would lower the total value created in the economy by $\$ 1.75$. In practical terms, for example, if the true SMC of electricity is $\$ 0.12$ per $\mathrm{kWh}$ and the price is set at $\$ 0.08$ per $\mathrm{kWh}$, then we will encourage people to leave some lights on when the value they are getting from doing so is less than the cost they are imposing on society.

\section{Efficient pricing of electricity}

In textbook competitive markets, price equals marginal cost, and all gains from trade are realized. But the relationship can break down for at least three reasons:

1. Externalities. If sellers in the market are highly competitive, but producing the good generates negative externalities, then competition will set a price below the social marginal cost to reflect only the marginal cost that the sellers have to bear. Because those sellers don't internalize the cost of externalities (by definition), the price will be too low, and too many sales will occur.

2. Market power of sellers. If the market is not highly competitive, then sellers may be able to make greater profit by raising prices above competitive levels. Because sellers have such "market power," prices will be too high, and too few sales will occur. Some transactions that would have created economic value will be stifled.

3. Failure to cover costs when price is equal to marginal cost. In some cases, generally ones in which firms have significant fixed costs, competitive pricing 
might not be sustainable because it does not generate enough revenue to cover a firm's total costs. In economics, these situations are referred to as "natural monopoly," because the presence of large fixed costs suggest that it would be more economically efficient to have one firm do all production. Standard examples include local distribution lines for electricity or telephones, because it is widely agreed that it does not make economic sense to have duplicate wires running down the street.

All three of these potential distortions exist in regulated electric utility markets. There are clearly large fixed costs and natural monopoly tendencies in local distribution, and probably also transmission, of electricity. As a result of this tendency toward monopoly, electric utilities are either regulated by a state agency or owned by a local government or consumer-owned cooperative, in part to prevent the electricity provider from exercising market power and raising price above competitive levels. At the same time, generation and distribution of electricity creates negative externalities.

So then what does economics bring to the question of how to recover fixed costs? The answer begins by recognizing the ideal scenario, in which the price of each $\mathrm{kWh}$ is set to reflect the social marginal cost of providing it, and customers understand that price and optimize their consumption in response to it. This would involve the price changing second by second, and consumers - or their "smart" devices — responding to those second by second changes. ${ }^{5}$ And it would involve price reflecting not just the utility's marginal cost of production, but also the cost of all externalities created.

In this scenario, the price would be very high at times when demand is strong, and there is a high probability of a supply shortage so that the marginal cost of producing one more $\mathrm{kWh}$ is potentially very high and would be much lower at low-demand times. It has long been known that such pricing could produce more or less revenue than the firm needs to cover its costs. ${ }^{6}$ But if there are fixed costs - which don't scale up with peak or total quantity sold - then there will be a tendency toward a revenue shortfall. That is, true fixed or sunk costs tend to create a revenue shortfall problem when electricity is priced to reflect marginal cost.

There is a countervailing effect, however, which is the failure to price externalities. Utilities seldom have to pay for the negative externalities that their business 
creates, but in order to create appropriate incentives for consumption they should still be adding those social costs to the volumetric price of electricity. Doing so would increase their revenues without increasing costs and bring them closer to breaking even, including covering their fixed costs. There is no logical or theoretical reason that the net effect of fixed costs and pricing-in externalities would necessarily cause efficient volumetric pricing of electricity to generate either positive or negative profits for the utility. But realistic calculations suggest that charging efficient volumetric prices would likely still lead the utility to lose money. ${ }^{7}$ And if society ever requires utilities to pay for the externalities they create, that will increase utility costs further and move utilities further from being able to recover their total costs while charging economically efficient prices.

Of course, utilities depart from this ideal pricing scenario in many ways, most importantly by charging prices that vary little, if at all, over time. Commercial and industrial customers typically face just a two-tier peak/off-peak pricing structure, while the vast majority of residential customers face no time variation in price at all. Absent a strong reason to think demand is more or less elastic at peak times, the most efficient time-invariant price is the average of the prices that would be charged in the ideal scenario (in which prices change minute by minute), which yields the same total revenue as under time-varying pricing. ${ }^{8}$ So the fact that utilities actually charge prices that vary little or not at all over time doesn't change the fundamental issue of how to recover fixed costs. Nor would appropriate time-varying pricing solve the problem.

In recent years, the fixed-cost recovery problem has grown as more costs have been added to utility operations that are not directly tied to providing an incremental $\mathrm{kWh}$ of electricity. For instance, energy efficiency programs, discounts to low-income customers, and subsidies for installing distributed generation are now costs that the utility must recover, but are not part of the social marginal cost of providing a $\mathrm{kWh}$ to a specific customer. In addition, energy efficiency programs and distributed generation have reduced demand and thus required that the revenue shortfall from marginal-cost pricing be made up over a smaller number of kWh. More generally, declining demand, regardless of the cause, is likely to increase the revenue shortfall that utilities (and regulators) will face if volumetric prices are set efficiently to equal SMC. 
The variety of fixed costs that a utility incurs raises a distinction between customerspecific fixed costs and system-wide fixed costs. Customer-specific fixed costs vary according to whether the customer receives service from the utility, regardless of how many $\mathrm{kWh}$ the customer consumes. These include incremental metering and billing costs for that customer, and maintaining the connection from the distribution system to the customer's meter. System-wide fixed costs cannot be attributed to a specific customer and are independent of the $\mathrm{kWh}$ consumed on the system. These include construction and maintenance of the local distribution networks, the corporate structure and public purpose programs, such as energy efficiency and distributed generation programs. The distinction has particularly important implications for discussions of equity or cost causality.

\section{Alternative approaches to covering a revenue shortfall}

Departures from pricing at SMC have implications for both economic efficiency and equity concerns. In discussing utility rate structures, the term "equity" can have two different meanings - the first consistent with some notion of fairness across customers with different consumption levels and patterns, and the second consistent with some notion of fairness across customers of different levels of income or wealth. For clarity, I will use "equity" for the first concept and "distributional effects" for the second.

I will assume from this point forward that efficient pricing, price set equal to SMC, results in a revenue shortfall. However, the opposite situation, excess revenue from setting price equal to SMC, can also occur. ${ }^{9}$ So I will focus on the question of how to increase revenues to the point that the utility can break even, including a fair return on capital invested. ${ }^{10}$

\subsection{Average-cost pricing}

For most of the history of utilities, the answer to such a revenue shortfall has been to raise the volumetric price of the electricity. Because utilities are generally monopolies facing fairly inelastic demand, it is almost always possible to raise the price enough to allow the firm to break even. This approach is often referred to as "average-cost pricing" because the price is set at a level to cover the average cost per $\mathrm{kWh}$, where that average is inclusive of both variable costs and fixed costs. As the example in Figure 1 demonstrated, however, setting price above social marginal cost creates deadweight loss by impeding some consumption that is socially valuable. Much of the economic analysis of regulatory 
pricing and taxation over the last 90 years has attempted to improve economic efficiency by developing alternate ways to raise the needed additional revenue while creating less deadweight loss.

Still, average-cost (AC) pricing remains widespread because it is so attractive on equity grounds. In its simplest implementation, AC pricing implies charging every customer — rich or poor, heavy user or light, residential or commercial — the same price per $\mathrm{kWh}$. Equally important, it means that all customers make payments above marginal cost to help cover the fixed costs, and that a customer's contribution to the extra revenue needed to cover fixed costs is proportional to that customer's usage. ${ }^{11}$

For instance, assume the marginal cost is $\$ 0.12$ per $\mathrm{kWh}$, but there are significant fixed costs so the utility must charge $\$ 0.22$ per $\mathrm{kWh}$ - an extra $\$ 0.10$ per $\mathrm{kWh}$ - to break even. Then a customer who consumes $100 \mathrm{kWh}$ is making a $\$ 10$ contribution toward the additional required revenue, while a customer who consumes $400 \mathrm{kWh}$ is making a $\$ 40$ contribution. Many people and policymakers find this allocation equitable.

Even on equity grounds, however, it is not obvious that one customer consuming four times as much electricity as another customer should make a four times larger contribution to the additional required revenue, when that additional revenue is needed to cover costs that are independent of the level of consumption by an individual or even by all customers in aggregate. For instance, it might be the case that the customer consuming only $100 \mathrm{kWh}$ receives a very high value from those units of consumption, while the heavier consumer might have a readily available alternative (e.g., self-generation), so is getting much less value from the utility.

\section{2 'Ramsey' pricing: Differentiated pricing based on demand elasticity}

The earliest contribution on the issue of raising revenue while minimizing deadweight loss, ${ }^{12}$ pointed out that if a consumer has more elastic (i.e., price-sensitive) demand, raising the price charged to that consumer creates greater deadweight loss relative to the amount of additional revenue it creates compared to another consumer with less elastic demand. Raising the price to customers with more elastic demand simply causes them to cut back their consumption substantially even though they value those units greater than SMC, creating more deadweight loss while purchasing fewer units and thus contributing less to the revenue requirement. Figure 2 illustrates that both D1 and D2 
consume Q0 when the price is set equal to SMC. But if the price is raised to $\mathrm{AC}$, much more additional revenue is extracted from D1, and less deadweight loss is created, than when price is raised for D2.

Figure 2. Illustration of the Impact of Demand Elasticity on DWL from Raising Price

The resulting "Ramsey pricing rule" says that in order to minimize deadweight loss while meeting the breakeven revenue requirement for the utility, groups of consumers with very inelastic demand should pay higher markups over marginal cost than groups of consumers with very elastic demand. This is much more than an abstract theoretical result. In fact, it describes well the outcome in which a utility gives special rates to commercial and industrial (C\&I) customers who credibly argue that they would otherwise locate elsewhere. The willingness of businesses to locate elsewhere if electricity rates are too high demonstrates high demand elasticity and implies that raising the rate to these customers will do more to reduce their demand than to actually bring in greater revenue. That resulting deadweight loss manifests as fewer jobs and less economic value created by these C\&I customers. ${ }^{13}$

Application of the Ramsey pricing rule, however, nearly always raises significant equity concerns. Customers with very inelastic demand, who receive higher prices under the rule, are those who have few alternatives and "need" the good. Charging those customers higher prices conflicts with many notions of equity.

\subsection{Fixed charges}

In most of the United States, residential electricity customers pay a fixed charge each month that is independent of the quantity they consume, though the size of the charge ranges across utilities from just a couple of dollars to $\$ 20$ or more. Fixed charges are a very attractive way to minimize deadweight loss while raising additional revenue, because they give customers no incentive to change their electricity consumption choices. Thus, if setting the volumetric price of electricity at SMC yields insufficient revenue, one common suggestion is to set a fixed charge that raises sufficient additional revenue to cover the revenue requirement.

A fixed monthly charge of $\$ 10, \$ 20$, or $\$ 30$ is unlikely to lead any customers to disconnect from the utility, because at least a basic level of electricity consumption is a 
necessity. ${ }^{14}$ And once customers decide to pay the fixed charge, they rationally would consider it no more relevant to how much electricity they consume than the same increase in rent, medical insurance, food, or any other expense. The decision of how much to consume would still be based on the incremental price of electricity.

Still, questions about the economic efficiency of such an approach have also been raised if customers base their decisions on imperfect information. If consumers don't pay much attention to their bills, they may not distinguish between the marginal price of electricity and their average price, inclusive of the fixed charge, or understand the impact on their overall bill. Convincing evidence of a similar information failure has been presented for more complex tiered billing structures that I will discuss below. Research, however, has not determined whether or not consumers are generally able to sort out a monthly fixed charge from the marginal price of electricity when making consumption decisions. Nonetheless, this is an area deserving of further study.

Practical concerns have also been raised about how the fixed charge concept might be applied beyond residential customers. A fixed monthly charge for commercial or industrial customers is rarely suggested. The reason for this distinction is clear: While households do range substantially in size, most still have between one and 10 individuals and a similar range in square footage of living space and other determinants of electricity demand. In contrast, C\&I customers have a much wider range of employees, sales, square footage, and other demand determinants. It would seem arbitrary and objectionable to impose the same fixed charge on an auto assembly plant as on a corner store, or a family living in a small apartment.

Some have suggested using a fixed charge that increases when the customer crosses certain consumption thresholds. If no customers are near the thresholds, then this approach could potentially segment customers into different fixed charge categories without creating perverse incentives for changing behavior. In reality, however, the distribution of customer usage is smoothly populated across nearly all consumption levels found among household customers, and the distribution among small commercial customers overlaps significantly with household customers. So such graduated fixed charge tariffs would create incentives for many consumers to reduce usage in order to drop down to a lower fixed charge. Effectively, the thresholds are points at which the 
price for an incremental $\mathrm{kWh}$ is drastically greater than SMC and is thus likely to create substantial deadweight loss.

Applying a uniform fixed charge even among residential customers nearly always raises objections on equity and distributional grounds. The equity argument is just the flip side of the discussion in favor of AC pricing: Why should a customer who consumes very little have to make as large a contribution toward covering fixed costs as a customer who consumes much more? The distributional argument is based on the accurate, but sometimes overstated, claim that wealthier households consume more electricity. For example, while this is true for customers of the three large investor-owned California utilities, most low-income customers are already on a separate tariff targeted specifically at the poor. ${ }^{15}$ Among moderate- and high-income customers, there is still a difference in average consumption, but it is much more modest.

\subsection{Tiered pricing}

Under tiered pricing the marginal price a customer faces changes with the quantity consumed. It also is often referred to as increasing-block or decreasing-block pricing, depending on whether the marginal price rises or falls with the customer's consumption. For example, an increasing-block price schedule might charge the customer $\$ 0.12$ for each of the first $300 \mathrm{kWh}$ the customer consumes during the month, $\$ 0.18$ for each additional $\mathrm{kWh}$ between $300 \mathrm{kWh}$ and $500 \mathrm{kWh}$, and $\$ 0.30$ for each $\mathrm{kWh}$ above 500 $\mathrm{kWh}$.

Tiered pricing was originally introduced in the decreasing-block form. That can be seen as a compromise of sorts between AC pricing and a fixed charge with lower constant pricing. As shown by the dashed vertical line in Figure 3, a fixed charge is just a very high price for the first tranche of $\mathrm{kWh}$ consumed during the billing period, and then a lower price for all additional $\mathrm{kWh}$, while AC pricing charges the same price for all $\mathrm{kWh}$. Under AC pricing, the additional revenue above SMC is raised proportionally to consumption, while with a fixed charge it is equally allocated among all customers regardless of consumption. Declining-block pricing (the dotted line in Figure 3) allocates more of the additional revenue needed to higher-demand consumers (the vertically striped area plus the horizontally striped area, for $\mathrm{D}_{\text {high }}$ ) than to lower-demand consumers (just the horizontally striped area, for $\mathrm{D}_{\mathrm{low}}$ ), but not proportionally more. 
Figure 3. From Fixed Charges to Decreasing-Block Pricing to Flat Rates

At the same time, because decreasing-block pricing implies above-AC pricing for lower-quantity units of consumption, the marginal price for higher-quantity units can be closer or equal to SMC, and can thus generate less deadweight loss for those units. Compared to fixed charges, however, decreasing-block pricing has the drawback that lower-consuming customers will face a very high marginal price and will respond by inefficiently cutting back consumption. To the extent that there are few or no customers on the lower-quantity tiers (if all customers have demand around $\mathrm{D}_{\text {high }}$ or greater), the impact is very similar to a fixed monthly charge, because nearly all customers contribute the same amount toward the additional revenue requirement. In that case, nearly all customers face the lowest marginal price.

In the last 20 years, increasing-block pricing has become much more prevalent in residential U.S. electricity tariffs than decreasing-block pricing. Arguments for increasing-block pricing are based on both distributional concerns and conservation goals. The distributional argument is that low-income households are more likely to be consuming more of their electricity at low-tier rates, and therefore increasing-block structures redistribute the revenue burden to wealthier households on average. Analysis suggests that the redistribution is quite modest if the utility also has a separate tariff for low-income households, as most utilities do. Furthermore, many lower-income households are made worse off by the increasing-block structure, and many higherincome households benefit from it. Overall, if the goal is to help lower-income households, programs that are more accurately targeted at them are likely to be more effective. $^{16}$

The foundational economic analysis I presented earlier demonstrates that reducing consumption creates net benefits to society only if the value of that consumption is less than the full social marginal cost. Thus, charging a price that includes the cost to society of externalities makes sense, but charging a price that is substantially above the full SMC will cause some consumption to be discontinued for which the customer values the service more than the marginal cost, even inclusive of the external marginal costs it imposes. Put differently, reduction of consumption that is not valued highly enough to 
justify the external costs it imposes on society is a worthy goal, but not all conservation is beneficial. Electricity regulators almost always recognize this reality even when they adopt increasing-block pricing, resulting in a plethora of special rates (or special baseline quantities that determine the quantities at which the increasing-block steps occur) for favored activities, such as electric heating or charging electric vehicles. That approach, however, puts the regulator in the position of trying to discern the consumer's value of each electricity use, a task that market economies eschew in general, because they recognize how poorly the government performs that task.

It is also not clear that increasing-block pricing actually lowers aggregate consumption among residential customers. While it does raise the marginal price for high-use customers above a revenue equivalent $\mathrm{AC}$ price, it also lowers it for low-use customers below the revenue equivalent AC price. If all customers are well-informed and respond efficiently to marginal price, then aggregate consumption is likely to fall. But customers' response to complex, multi-step, increasing block tariffs corresponds more closely to a model in which they use a heuristic that reflects the average price they face. ${ }^{17}$ If the increasing-block tariff is revenue-neutral with the AC price schedule, then the average price across all units consumed must be the same, and increasing-block pricing would generate no net reduction. ${ }^{18}$ Analysis of a very steep increasing-block tariff in place for a large California utility yielded an estimated $2.3 \%$ reduction in residential consumption assuming customers responded efficiently, but in practice the tariff probably causes an increase of about $0.3 \%{ }^{19}$

The economic efficiency of increasing-block pricing, compared to AC pricing, depends on the reduction in deadweight loss for customers who respond to a price that is less than AC (but still presumably above SMC) versus the increase in deadweight loss for customers who respond to a price that is greater than AC. The net effect on economic efficiency will almost surely be negative. ${ }^{20}$ Analysis for one California utility estimates that compared to AC pricing, the increasing-block tariff the utility uses increases deadweight loss by an amount equal to about $3 \%$ of revenues received from residential customers.

Finally, for the same reason as with monthly fixed charges, tiered pricing makes very little sense in the context of C\&I customers. Because there is a much wider range of 
electricity demand across companies than across residential customers, it is hard to see how a common tiered pricing structure could be applied to all C\&I customers, or even large subsets of them. Some have suggested that the baseline quantities on which the tiers are based could be a function of past usage by the customer, but this creates incentives for distorting consumption in order to alter the baseline. ${ }^{21}$

\subsection{Minimum bills}

The mathematics of a minimum bill is simple, but frequently ignored: A minimum bill is a combination of a fixed charge and a certain quantity of free electricity. For instance, if the price of electricity is $\$ 0.10$ per $\mathrm{kWh}$ and there is a minimum bill of $\$ 8$ per month, that is identical to a fixed charge of $\$ 8$ per month plus receiving the first 80 $\mathrm{kWh}$ for free. Thus, a minimum bill is the combination of a fixed charge and an extreme version of increasing-block pricing, as illustrated in Figure 4. If the minimum bill is small enough, implying a quantity of free electricity that is less than nearly every customer uses, then the fixed charge and free electricity exactly offset, and the minimum bill has no impact on either the bills of the customers or the finances of the utility.

\section{Figure 4. Illustration of Effective Marginal Price of Electricity Under Minimum Bills}

If the minimum bill is high enough to actually raise the amount owed to the utility by a significant number of customers, then it creates very perverse incentives for those customers, reducing their cost of incremental consumption to zero until they hit the minimum bill. Zero is well below the SMC for nearly every unit of electricity a utility sells, so a minimum bill has the effect of encouraging electricity consumption from which the customer gets much less value than is imposed on society by its production.

Thus, from both an efficiency and equity point of view, minimum bills are inferior to the alternative of setting price equal to SMC for the equivalent quantity and then charging a fixed charge that is smaller than the minimum bill. For instance, returning to the example above with a minimum bill of $\$ 8$ and marginal price of $\$ 0.10$ per $\mathrm{kWh}$, let's say the true SMC is $\$ 0.06$ per $\mathrm{kWh}$. In that case, it would be more economically efficient and more equitable to charge $\$ 0.06$ per $\mathrm{kWh}$ for the first $80 \mathrm{kWh}$ plus have a fixed charge of $\$ 3.20$. That would have no impact on the bills of customers consuming 
more than $80 \mathrm{kWh}$. It would lower the bill of customers consuming less than $80 \mathrm{kWh}$, but it would still give them an efficient incentive not to waste electricity. ${ }^{22}$

\subsection{Demand charges}

It is unclear why demand charges still exist. Charging customers for their peak usage during a billing period has been supported as an approximation to a customer's demand during system peak periods, but it was never a very good approximation, as the customer's peak may not be coincident with the system peak. ${ }^{23}$ Furthermore, the single highest consumption hour of the billing period is not the only, and may not even be the primary, determinant of the customer's overall contribution to the need for generation, transmission, and distribution capacity.

In any case, the value of such approximations has been mostly eliminated with smart meters that record usage in hourly or shorter intervals. Smart meters permit timevarying price schedules that can easily be designed to more effectively capture the timevarying costs that a customer imposes on the system. Demand charges could be justified when "dumb" meters could only record aggregate consumption and peak consumption, but could not even log information on when that peak occurred. ${ }^{24}$

An additional explanation for demand charges is that they capture the customerspecific fixed cost of providing a certain level of service capacity to the customer's site. Such capacity, however, is established by making up-front and largely sunk investments in the local distribution network and the final connection to the customer. These may constitute a substantial share of the fixed costs that create the concerns addressed in this paper, but the cost of such capacity is determined by the attributes of the connection, not by the customer's peak usage after the connection is established. A monthly fixed charge based on the customer's service capacity would more appropriately capture these costs.

The use of demand charges has also created a large market of consultants advising customers on how to reduce their peak demand that is wasteful from a societal point of view. Customers faced with demand charges place high private value on reducing their very highest hour of usage, even if there are other hours in which usage is nearly as high, and even if none of those hours are coincident with system peak times.

At their very best, demand charges may not do a bad job of capturing some customer-specific fixed costs and may quite imperfectly reflect the time-varying costs of 
the customer's consumption. But customer-specific fixed charges that reflect service levels and time-varying pricing accomplish these goals much more effectively, so why would one use demand charges ? $^{25}$

\section{Conclusion}

In the end, there is no good answer to the question of how a utility should recover fixed costs, but there are less bad ones. Ratemaking should begin by setting prices to reflect the full time-varying short-run social marginal cost of generating and delivering electricity. These prices should include "adders" for the externalities created, even if the utility is not required to make explicit payments for those social costs, as is the case for most externalities today. As a result, the revenue from these adders can be used to close the gap between the revenue collected from efficient pricing and the revenue the utility needs to cover its costs. ${ }^{26}$

In general, however, efficient pricing that reflects full social marginal cost will still not cover all fixed and variable costs of the utility. Increasing the volumetric price of electricity has appeal on equity grounds, because it allocates the revenue shortfall across users based on the quantity they consume. However, it also raises the marginal price of electricity above social marginal cost and therefore distorts consumption choices. As customers have more choices of energy supply - e.g., between electrified and liquid fuel-based transportation or between distributed generation and grid supply - the deadweight loss from sending distorted price signals is likely to rise. ${ }^{27}$ While raising the volumetric price has been the most common policy choice for many decades, it is particularly important now to consider alternatives.

The leading alternative is higher fixed charges, but they can lead to significant equity concerns and even some potential efficiency issues. Recovering customer-specific fixed costs through fixed charges - calibrated to reflect cost differences in service levels - is quite appealing on both equity and efficiency grounds. But a fixed charge that is the same for customers with massively different demands will violate a common sense of equity, and a so-called "fixed charge" that is based on past or current usage is effectively volumetric and creates deadweight loss.

Objections to any level of fixed charge based on distributional consequences ignore the fact that the alternative of recovering all revenues through volumetric charges 
arbitrarily harms many low-income customers and benefits many high-income customers. Targeted means-tested programs that help low-income households are a more appropriate response to these concerns.

The more difficult fixed-cost recovery issue results from system-wide fixed costs that cannot be attributed to any one customer. Because such costs are substantial, pricing electricity at social marginal cost and having a fixed charge that reflects customerspecific fixed costs is still likely to leave a revenue shortfall. There is no ideal policy for recovery of the additional needed revenue, but the least bad from both an efficiency and equity point of view is almost surely a combination of higher fixed charges and an adder to time-varying volumetric rates. For the reasons I have discussed, it is very difficult to justify demand charges, tiered rates, or minimum bills as part of the solution. Nor would frequent rate cases, formula rate plans, or decoupling solve the fixed-cost recovery problem.

While it may be unsatisfying that economics and policy analysis does not yield a clear solution, it does yield valuable guidance. Incorporating that guidance in electricity ratemaking would be a very useful first step in rationalizing prices. 


\section{References}

Berg, S.V., Tschirhart, J., 1988. Natural Monopoly Regulation: Principles and Practice. Cambridge Surveys of Economic Literature Series, Cambridge University Press.

Boiteux, M., 1949. La tarification des demandes en point: application de la theorie de la vente au cout marginal. Revue General de l'Electricite. 58, 321-340 (translated as Peak Load Pricing. Journal of Business. 33, 157-179).

Borenstein, S., 2000. Understanding Competitive Pricing and Market Power in Wholesale Electricity Markets. Electricity Journal. 13, 49-57.

Borenstein, S., 2005. "Time-Varying Retail Electricity Prices: Theory and Practice," in Griffin and Puller, eds., Electricity Deregulation: Choices and Challenges, Chicago: University of

Chicago Press.

Borenstein, S., 2011. Regional and Income Distribution Effects of Alternative Retail Electricity Tariffs, Energy Institute at Haas Working Paper \#225, UC Berkeley, October.

Borenstein, S., 2012. The Redistributional Impact of Non-Linear Electricity Pricing. American Economic Journal: Economic Policy. 4, 56-90.

Borenstein, S., 2013. Effective and Equitable Adoption of Opt-In Residential Dynamic Electricity Pricing. Review of Industrial Organization. 42, 127-160.

Borenstein, S., 2014. Money for Nothing? post on Energy Institute at Haas blog, May 12. Available at https://energyathaas.wordpress.com/2014/05/12/money-for-nothing/

Borenstein, S., 2015. "The Decline of Sloppy Rate Making" post on Energy Institute at Haas blog, May 12. Available at https://energyathaas.wordpress.com/2015/08/24/the-decline-ofsloppy-electricity-rate-making/

Borenstein, S., Bushnell, J.B., 2015. The U.S. Electricity Industry After 20 Years of Restructuring. Annual Review of Economics. 7, 437-463.

Borenstein, S., Davis, L.W., 2012. The Equity and Efficiency of Two-Part Tariffs in U.S. Natural Gas Markets. Journal of Law and Economics. 55, 5-128.

Borenstein, S., Holland, S.P., 2005. On the Efficiency of Competitive Electricity Markets With Time-Invariant Retail Prices. Rand Journal of Economics. 36, 469-493.

Ito, K., 2014. Do Consumers Respond to Marginal or Average Price? Evidence from Nonlinear Electricity Pricing. American Economic Review. 104, 537-563.

Ramsey, F.P., 1927. A Contribution to the Theory of Taxation. The Economic Journal. 37, 47-61.

Schwartz, Lisa (editor)., 2016. Recovery of Utility Fixed Costs: Utility, Consumer, Environmental and Economist Perspectives. Lawrence Berkeley National Laboratory report 1005742, June. Available at http://feur.lbl.gov.

Steiner, P.O., 1957. Peak Loads and Efficient Pricing. Quarterly Journal of Economics. 71, 585610.

\footnotetext{
${ }^{1}$ Of course, the true cost of pollution is itself controversial, but any policy to address externalities confronts this issue, either implicitly or explicitly, when costly actions are taken to reduce pollution. Addressing the externality cost question directly is critical to arriving at transparent and credible environmental and energy policy.

${ }^{2}$ It is worth noting that because economic efficiency starts with setting price equal to short-run marginal cost, it avoids the debate about which costs are fixed. Rather, the focus of revenue collection is on covering total costs (a much less controversial figure), and the question becomes how much additional revenue must be raised to do so starting from the point at which price equals short-run social marginal cost.

${ }^{3}$ Some analysts have argued that price should reflect long-run marginal cost (LRMC) in order to reflect the capital costs of production. This would not in general yield economic efficiency. For instance, if a system is underbuilt and has a shortage of capacity, economic efficiency dictates that price increase to reflect the scarcity value of the electricity at each moment, regardless of the cost of capital to expand the system's capacity in the longer run. LRMC is appealing as a rough guideline for financing capital expansion, but it is not a good guide to economic efficiency of pricing. Precise economic analysis starts with pricing
} 
efficiently, which then makes clear the size of the revenue shortfall. The question of how to make up that shortfall is the subject of this volume. Electricity also differs from many markets due to the need to balance supply and demand with no storage. Borenstein (2000), particularly footnote 1, discusses application of the concepts to that case.

${ }^{4}$ Who bears that loss depends on the price at which a particular deal would have been made. The point is that when the buyer values the good more than it would cost the seller to supply it, there are gains from trade, and failure to make such deals imply a failure of anyone to capture those gains.

${ }^{5}$ Though we are institutionally quite far from this scenario, all the technology for it exists and is, in fact, already used for trading financial instruments. It would also be straightforward to offer alternatives to customers who don't want to be exposed to such price volatility (Borenstein 2013).

${ }^{6}$ Borenstein (2000) presents a more technical version of this argument. Boiteaux (1949) and Steiner (1957) first made these points.

${ }^{7}$ See Borenstein and Bushnell (2015), footnote 26.

${ }^{8}$ Borenstein and Holland (2005), p. 475.

${ }^{9}$ For instance, utilities that have a large supply of hydroelectric power from dams built many decades ago, but still must generate incremental power from fossil-fuel plants, may very well have a SMC that now exceeds their average cost per $\mathrm{kWh}$.

${ }^{10}$ Some observers have suggested that increasing the frequency of rate adjustments can address the profit shortfall problem. See the papers in Schwartz (ed.), 2016. If regulators systematically underestimates cost increases or overestimates quantities demanded, then infrequent resetting of rates will create a perpetual revenue shortfall. Although this is a concern for utilities and the regulatory process, it is quite apart from the problem of recovering utility fixed costs. Even if rates were reset daily, the presence of significant fixed costs would mean that economically efficient electricity prices would still likely fail to raise sufficient revenue to cover all of the utility's costs, for the reasons discussed above.

${ }^{11} \mathrm{AC}$ pricing can also be implemented in a time-varying context by imposing either a constant dollar adder to price in each period or a constant proportional markup. See Borenstein (2005).

12 Ramsey (1927).

${ }^{13} \mathrm{C} \& \mathrm{I}$ customers that are willing to relocate demonstrate that elasticity comes not just from a customer changing quantity consumed, but also from the customer relocating to purchase from a different seller.

${ }^{14}$ The argument is not as convincing in natural gas distribution, because some households could indeed be on the margin of disconnecting from the utility and using only electricity or liquefied petroleum gas, as discussed by Borenstein and Davis (2012). Virtually all U.S. households are customers of an electric utility, but only about half of households are customers of a natural gas utility. If distributed electricity storage becomes more cost-effective, however, high fixed monthly charges for electric service might one day also lead to "cutting the cord."

${ }^{15}$ Borenstein (2011).

${ }^{16}$ Borenstein (2012).

${ }^{17}$ Ito (2014).

${ }^{18}$ This argument assumes that the average demand elasticity is the same for lower-consuming customers as for higher-consuming customers. Ito tests that assumption and finds no statistical difference between the groups.

${ }_{19}^{19}$ Ito (2014).

${ }^{20}$ Borenstein (2012). The reason for this is that the amount of deadweight loss generated by pricing above SMC goes up approximately with the square of the P-SMC differential. In that case, a simple mathematical proof shows that the minimum deadweight loss results from charging all customers the same differential that is, AC pricing.

${ }^{21}$ Borenstein (2014) discusses a similar issue in which the baselines used to determine what customers are paid for reducing consumption in a billing period are based on each customer's past usage.

${ }_{22}^{22}$ The fact that some customers use less than $80 \mathrm{kWh}$ and the volumetric price is above marginal cost implies a slight revenue shortfall. This could be offset by a small increase in either the fixed charge or the lower-tier volumetric price. To be concrete, in this example if 10 percent of customers were below $80 \mathrm{kWh}$ and that group of customers consumed an average of $50 \mathrm{kWh}$, then this alternative tariff would require either setting the fixed charge (for all customers) at $\$ 3.32$ instead of $\$ 3.20$ or setting the volumetric charge at about $\$ 0.0616$ instead of $\$ 0.06$ for quantities up to $80 \mathrm{kWh}$. Either would leave the utility with the same profits as the proposed minimum bill. 
${ }^{23}$ Recently, some have started using "demand charge" to refer to a fee that is based on a customer's use during the system-wide peak demand. This is a form of time-varying pricing similar, though inferior, to what is known as "critical peak pricing." The discussion of demand charges here does not apply to that newer definition.

${ }^{24}$ Most C\&I customers now have meters that can record time-varying consumption. The majority of residential customers do not yet have such "smart" meters, but the meters they have also cannot record peak consumption needed for a demand charge. Switching them to the technology for a demand charge would cost nearly as much as the technology for time-varying pricing.

${ }^{25}$ Berg and Tschirhart (1988) propose a system under which customers purchase fuse capacities from the utility, which limits their maximum power consumption. With the progress in technology over the last few decades, this could no doubt be done in a more sophisticated way, but still only makes sense to the extent it reflects real costs imposed by the customer's peak usage.

${ }^{26}$ Even if regulators are unwilling to, or restricted from, imposing explicit adders to reflect externalities, this still suggests that when they mandate markups of volumetric prices above the utility's marginal cost as virtually all regulators do - those markups would be more economically efficient if they were calibrated to reflect variations in the externalities created by incremental generation.

${ }^{27}$ See Borenstein (2015). 


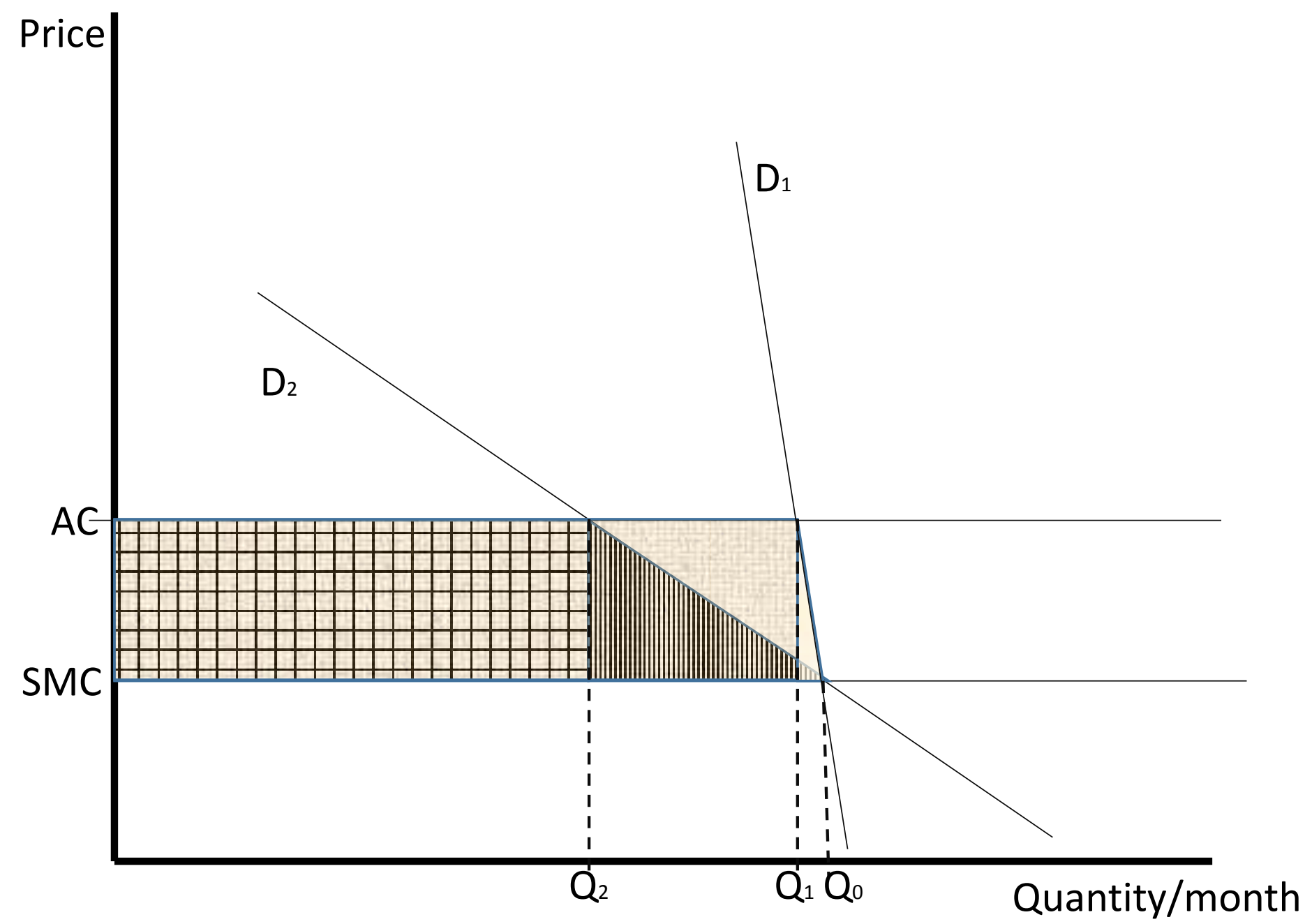




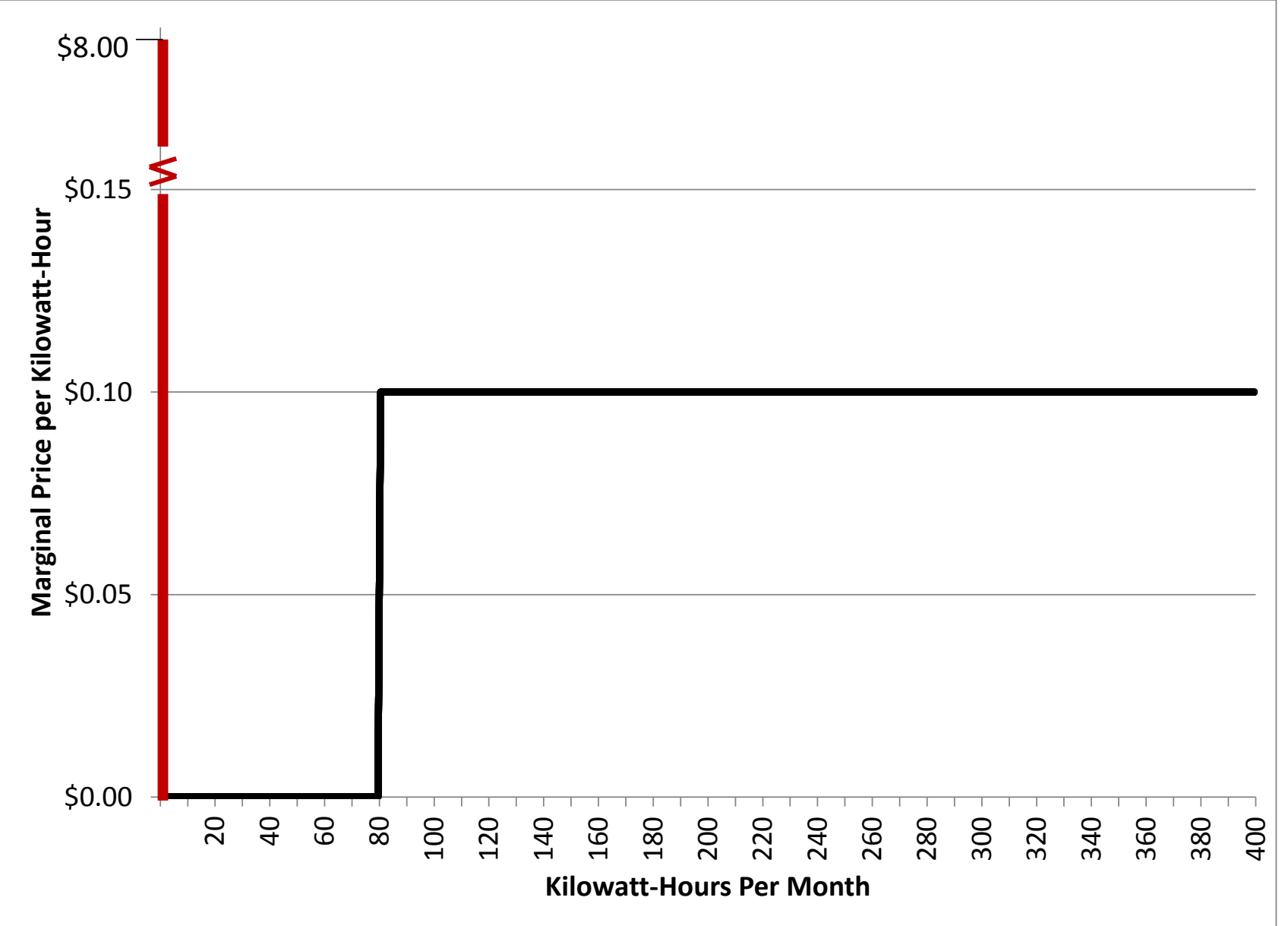

Illustration of Rate Structure with Minimum Bill (Min Bill $\$ 8, p=\$ 0.10 / \mathrm{kWh})$ 